\title{
Antibacterial activity of di-butyl phthalate isolated from Begonia malabarica
}

\begin{abstract}
Natural products from medicinal plants either as pure compounds or as standardized extracts provide unlimited opportunities for new drug leads because of the unmatched availability of chemical diversity. Begonia malabarica Lam. is one of the medicinally important herbs belonging to the family of Begoniaceae. It is reported that the leaves are used to treat respiratory infections, diarrhea, blood cancer and skin diseases. The whole plant possesses a variety of secondary metabolites. Isolation of such compounds will add more novel bioactive structures that are of interest to screen and select potential lead compounds to discover and develop drugs in the modern pharmaceutical sector. Against this backdrop, Begonia malabarica was extracted with various solvents and bioactive compounds were isolated using chromatographic techniques. One of the bioactive compounds isolated from it was colorless or pale yellow oily compound that is soluble in chloroform. The structure of the compound was elucidated as di-butyl phthalate with the help of spectral data such as FT-IR, MS, ${ }^{1} \mathrm{H}-\mathrm{NMR}$ and ${ }^{13} \mathrm{C}-\mathrm{NMR}$. This is the first report to the family of Begoniaceae. The compound is reported to have antibacterial and anticancer properties.
\end{abstract}

Keywords: chromatography, extraction, structural elucidation, antibacterial activity
Volume 5 Issue 2 - 2018

\author{
Thiyagaraj Mini Shobi, Madepalli Byrappa \\ Gowdu Viswanathan \\ Department of Botany, Bharathidasan University, India
}

Correspondence: Viswanathan MBG, Professor, Centre for Research and Development of Siddha-Ayurveda Medicines (CRDSAM), Department of Botany, Bharathidasan University, Tiruchirappalli 620024, Tamil Nadu, India, Email vinaabdu@gmail.com

Received: November 05, 2017 | Published: March 29, 2018

\section{Introduction}

Begonia malabarica L. is an important medicinal plant belonging to the family of Begoniaceae. This plant is used to treat many human ailments. Its leaves are substituted for Tamarind (Tamarindus indica L., Caesalpinoideae), cooked and consumed by the Palliyan tribe in Tirunelveli District of Tamil Nadu in India. Consumption of boiled leaves is practiced to treat stomach ulcer, diarrhea, stomachache, respiratory problems, and skin diseases. ${ }^{1}$ Leaves are used as wild edible by the Kani Tribe in Kanyakumari District of Tamil Nadu in India that contain high content of phenolic and flavonoid compounds and exhibit free radical scavenging activity. ${ }^{2}$ Their counterparts in Tirunelveli District of Tamil Nadu consume leaves to treat venereal diseases and cool the body. ${ }^{3}$ Plant is rich with vitamin $\mathrm{C}$ and its juice is consumed for blood purification and for treating fever. ${ }^{4}$ Leaf juice with a pinch of salt is consumed to treat giddiness and leaf paste is applied to treat foot sores. ${ }^{5}$ The secondary metabolites including terpenes, polyphenols, alkaloids and some glycodsides are largely responsible for the individual properties of the plants such as aroma, flavour, color and medicinal actions. ${ }^{6}$

There are a few reports of occurrence of phthalates in plants. Ten compounds including dioctyl phthalate, butyl isobutyl phthalate, n-heptacosane, lophenol, docosanyl ferulate, tetracosanyl ferulate, hexacosanyl ferulate, octacosanyl ferulate, pterostilbene, and 4'-methoxy-3',7-dihydroxy-flavone were reported from petroleum ether and ethyl acetate extract fractions of Dracaena cochinensis. ${ }^{7}$ Di-(2-ethyl) hexyl phthalate was reported from the leaves of Cassia auriculata. ${ }^{8}$ Bis(2-methylheptyl) phthalate was reported from the aerial parts of Hypericum hyssopifolium. ${ }^{9}$ Di-isooctyl phthalate was reported in Limonium bicolor. ${ }^{10}$ Bis (2-ethylhexyl) phthalate was reported from the roots of Euphorbia hylonoma. ${ }^{11}$ GC-MS analysis of essential oil from the skin of water caltrop showed the presence of diethyl phthalate. ${ }^{12}$ Root exudates of barnyard grass, Echinochloa crus-galli also reported to have diethyl phthalate. ${ }^{13}$ Di(2-ethylhexyl) phthalate was reported after its isolation from the leaves, root and bark of Alchornea cordifolia. ${ }^{14}$ Isolation of di-butyl phthalate is reported here for the first time to the family of Begoniaceae from Begonia malabarica by us.

\section{Materials and methods}

\section{Collection of plant material}

The plant material was collected from Tirunelveli district of Tamil Nadu in India and used for scientific investigation. Voucher specimens (MBV \& CR 1293) were prepared and deposited in the Herbarium of the Centre for Research and Development of Siddha-Ayurveda Medicines (CRDSAM), Department of Plant Science, Bharathidasan University, Tiruchirappalli, Tamil Nadu, India, after authentication by Prof. MB Viswanathan, for reference.

\section{Extraction of plant material}

Whole plants were collected, shade-dried, powdered and hotextracted using Soxhlet apparatus. The extract thus collected was filtered and concentrated at $60^{\circ} \mathrm{C}$ in a Rotary Evaporator (Yamato VR300-RE300-CF300-BM510, Muromachi, Japan).

\section{Isolation}

The concentrated extract $(5 \mathrm{~g})$ was dissolved with $30 \mathrm{ml}$ methanol, added $100 \mathrm{ml}$ petroleum ether for liquid-liquid separation and collected methanol-soluble portion only for further analysis. Then, chloroform and water (50:50) was added, collected water-soluble portion, concentrated in the Rotary Evaporator and chromatographed on a silica gel column (100-200 mesh). Elution process was performed using a solvent mixture of chloroform/methanol with increasing amount of methanol. Successive fractions were collected and dried using the Rotary Evaporator. The profile of column fractions was monitored by thin layer chromatography (TLC) using pre-coated TLC plate of silica gel $60 \mathrm{~F}_{254}$ (MERCK, Darmstadt, Germany) for $0.2 \mathrm{~mm}$ thickness to confirm the similarities of elutes. The number and color of the spots were visualized through UV Chamber and recorded their $\mathrm{R}_{\mathrm{f}}$ values. 


\section{HPTLC Analysis}

High Performance Thin Layer Chromatography (HPTLC) equipped with CAMAG (Switzerland) Linomat V sample applicator fitted with a $100 \mu$ l syringe (Hamilton Bonaduz, Switzerland) was used to develop fingerprinting profile. Samples were loaded with nitrogen gas supply for simultaneous drying of bands. A $10 \mu \mathrm{l}$ as 6.0 $\mathrm{mm}$ band length in $10 \times 10$ Silica gel $60 \mathrm{~F}_{254}$ TLC plate was loaded using syringe and kept in TLC twin trough developing chamber (after saturation with solvent vapour) with respective mobile phase. The plate was developed in the respective mobile phase chloroform and methanol (9:1) up to $70 \mathrm{~mm}$ and dried using hot air oven to evaporate solvents from the plate. Then, the plate was fixed with the scanner stage for scanning at $254 \mathrm{~nm}$. The peak table, peak display and peak densitogram were identified. Finally, the plate was kept in photo documentation chamber and captured images at UV 366 and $254 \mathrm{~nm}$.

\section{Structural characterization}

Melting point and m.m.p. of the compound were recorded. Spectral data were collected by using UV-Visible Spectrophotometer (1800, Shimadzu, Kyoto, Japan), Fourier Transform-Infrared Spectroscopy (FT-IR) (equipped with L1600400 Spectrum Two DTGS, Perkin Elmer, Massachusetts, USA), ${ }^{1} \mathrm{H}$ NMR and ${ }^{13} \mathrm{C}$ NMR AV 400-Bruker $400 \mathrm{MHz}$ High Resolution Multinuclear FT-NMR Spectrophotometer (Massachusetts, USA), and GC-MS 7890 A, MS 5975 equipped with HP 5 MS column (Agilent, California, USA). The data thus collected were used to elucidate the structure of the compound.

\section{Antibacterial activity}

Agar-well diffusion method (15) was followed. Muller-Hinton Agar (MHA) (HiMedia, Mumbai, India) plates were swabbed (sterile cotton swab) with $24 \mathrm{~h}$ old broth culture of the respective bacteria. A sterile cork-borer was used tfigo place wells, each measuring $8 \mathrm{~mm}$ in diameter in each of the plate. Test sample was loaded into the wells with $100,50,25,12.5$ and $6.25 \mathrm{mg} \mathrm{ml}^{-1}$ concentration using sterilized dropping micropipettes. The plates were incubated at $37^{\circ} \mathrm{C}$ for $18-24$ h. Experiments were conducted thrice and diameters of the inhibition zones were recorded and averaged to measure antibacterial activity.

\section{Results}

The compound was isolated by column chromatography using chloroform and methanol (9:1) ratio as elute and the purity of the compound was confirmed by HPTLC (Figure 1). A single fluorescent blue spot was visualized under UV Chamber at $254 \mathrm{~nm}$ with $\mathrm{R}_{\mathrm{f}}$ of 0.55 .

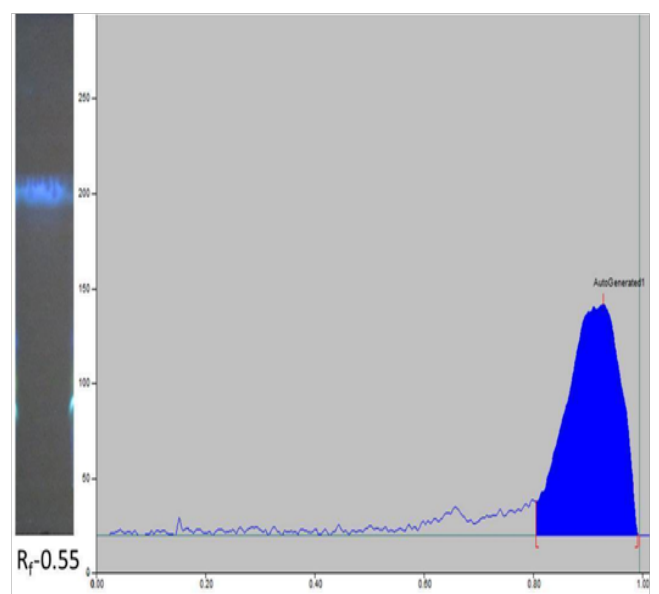

Figure I HPTLC chromatogram of dibutyl phthalate.

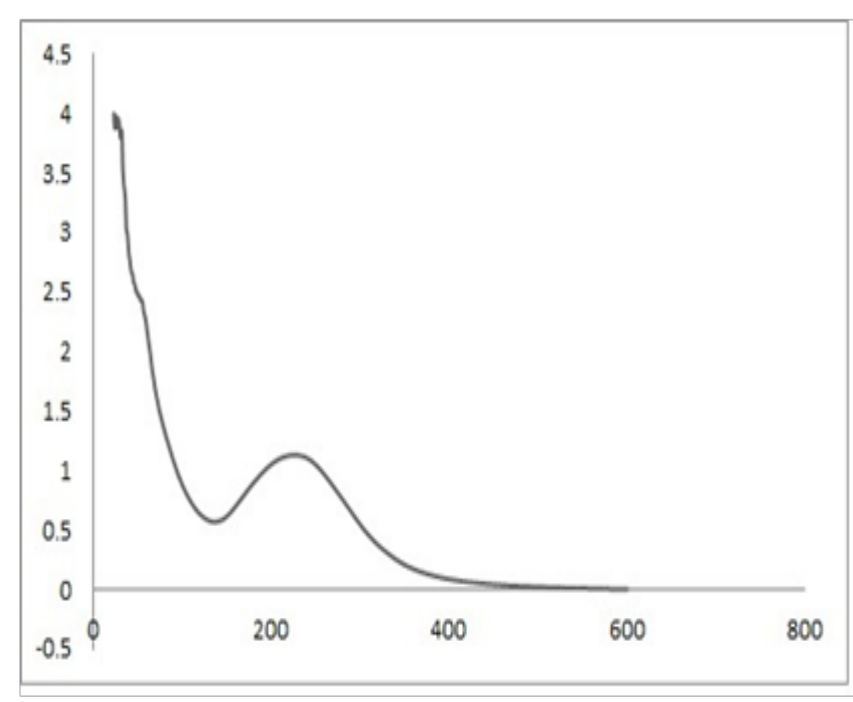

Figure 2 UV-Vis spectrum.

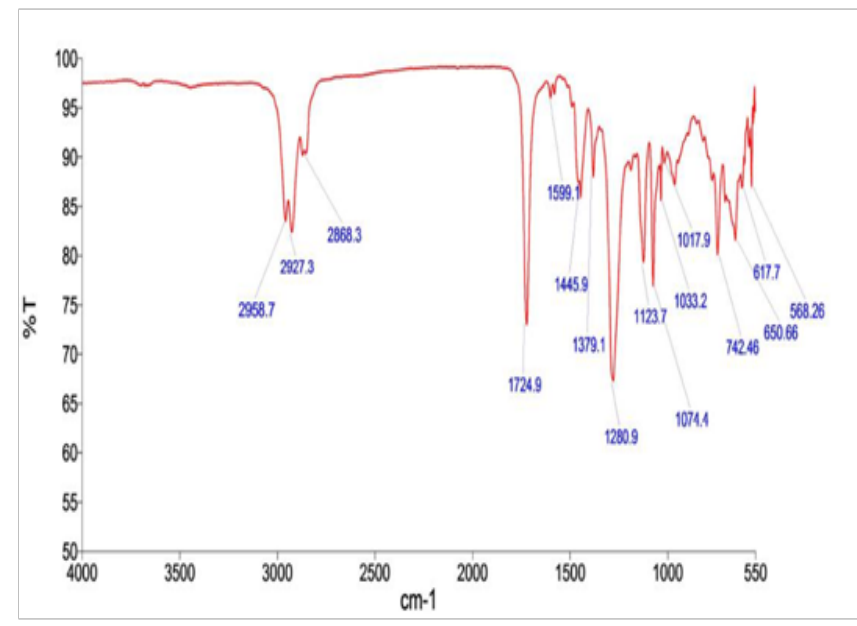

Figure 3 FT-IR spectrum.

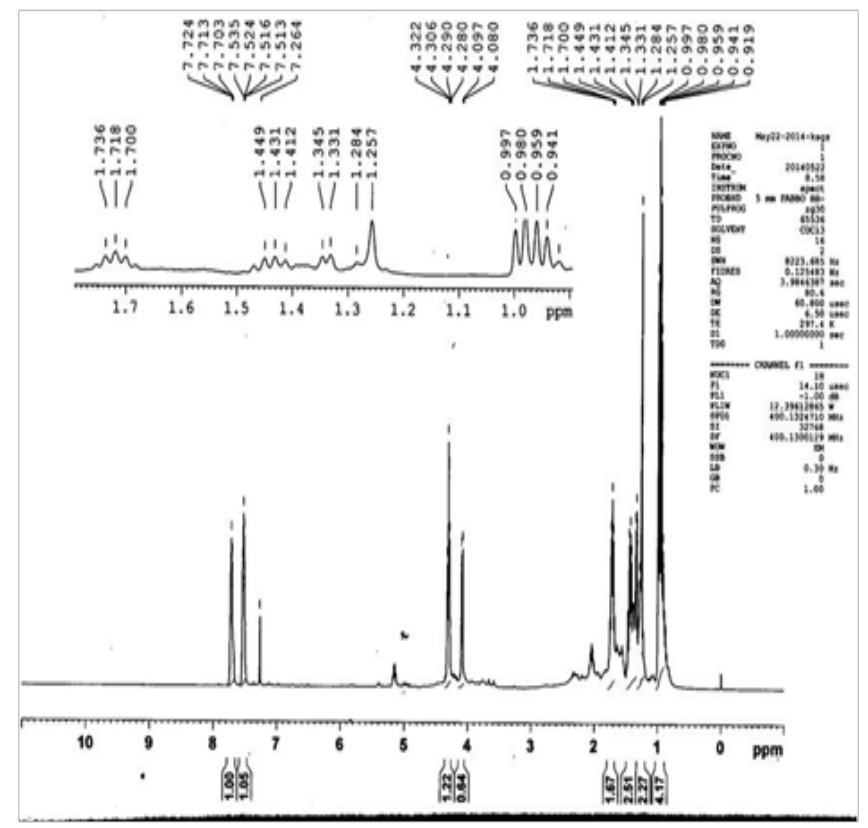

Figure 4 'H NMR spectrum. 


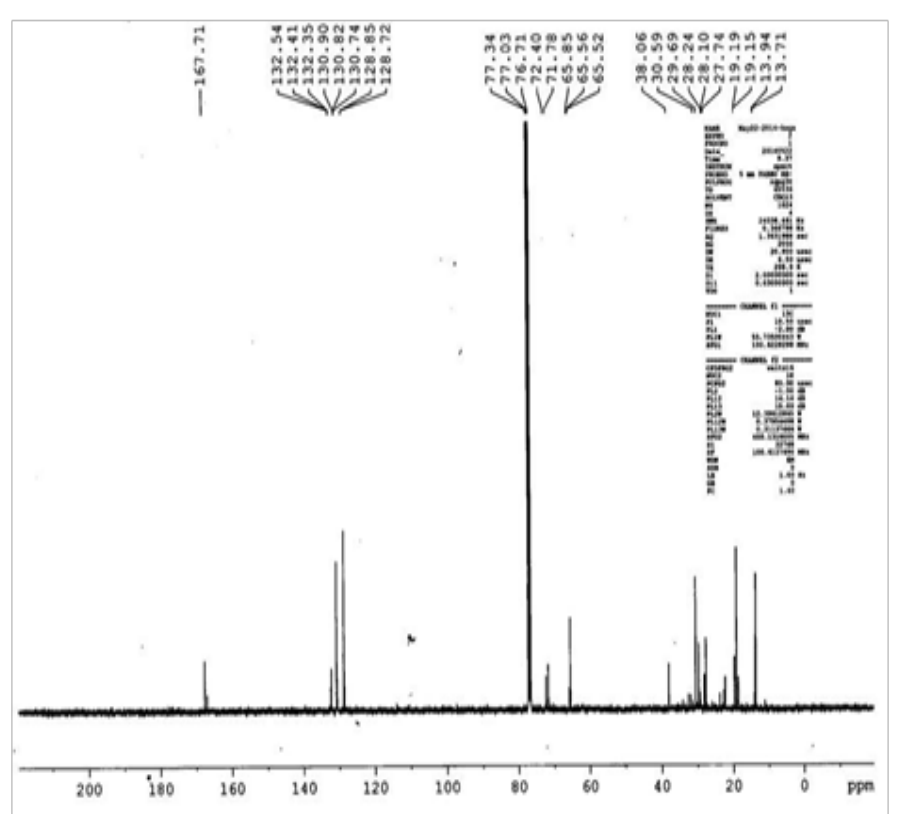

Figure $5{ }^{13} \mathrm{C}$ NMR spectrum.

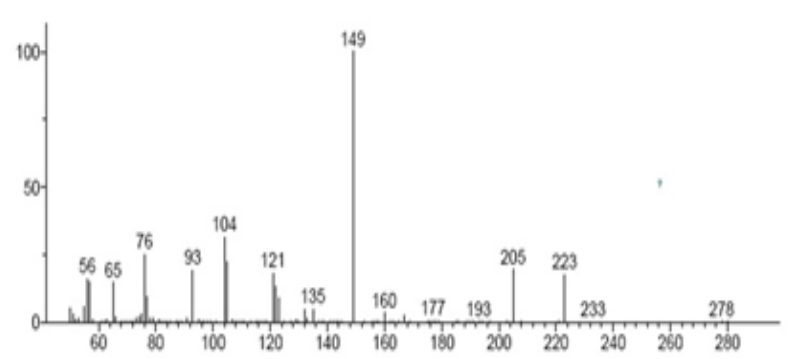

Hit 1: Dibuty phthalate

$\mathrm{C} 16 \mathrm{H} 22 \mathrm{O} 4$

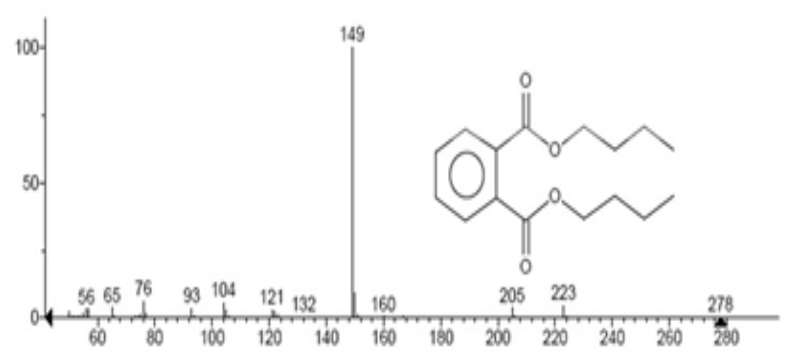

Figure 6 Mass spectrum.

Dibutyl phthalate $\left(\mathrm{C}_{16} \mathrm{H}_{22} \mathrm{O}_{4}\right)$, pale yellow oily compound, yield: $500 \mu \mathrm{l}(0.01 \%)$. Boiling point: $340-343^{\circ} \mathrm{C}$, UV $\left(\lambda_{\max }\right)$ : in chloroform 231 (Figure 2). FT-IR ( $\left.\mathrm{cm}^{-1}\right): 1724.9$ (ester carbonyl), 1280.9 and 1074.4 (-C-O-stretching), 742.46 (ortho disubstitution) (Figure 3). ${ }^{1} \mathrm{H}$ NMR ( $\delta \mathrm{ppm}): \mathrm{CDCl}_{3}-\mathrm{d}_{6}, 400 \mathrm{MHz}, 7.724(2 \mathrm{H}, d d), 7.535(2 \mathrm{H}, d d)$, $4.322\left(4 \mathrm{H}, t,-\mathrm{O}-\mathrm{CH}_{2}\right), 1.736-1.449\left(4 \mathrm{H}, m,-\mathrm{CH}_{2}\right), 1.345-1.284(4 \mathrm{H}$, $\left.m,-\mathrm{CH}_{2}\right), 0.919\left(6 \mathrm{H}, t,-\mathrm{CH}_{3}\right)$ (Figure 4$) .{ }^{13} \mathrm{C} \mathrm{NMR}(\delta \mathrm{ppm}): \mathrm{CDCl}_{3}-\mathrm{d}_{6}$, $400 \mathrm{MHz}, 167.71(\mathrm{C}=\mathrm{O}), 132.54(\mathrm{C}), 130.90,128.85$ (CH, Aromatic), $65.85\left(-\mathrm{O}-\mathrm{CH}_{2}\right), 30.59,19.17\left(-\mathrm{CH}_{2}\right), 13.82\left(-\mathrm{CH}_{3}\right)$ (Figure 5). Mass $(\mathrm{m} / \mathrm{z}): 278\left(\mathrm{M}^{+}\right.$peak) (Figure 6).

\section{Antibacterial activity}

Dibutyl phthalate (Figure 7) showed $9 \mathrm{~mm}$ zone of inhibition against Staphylococcus epidermidis, Strephtococcus pneumoniae, Escherichia coli, Micrococcus luteus, Klebsiella pneumoniae, Shigella flexneri, Vibrio cholerae and P. aeruginosa at the concentration of 100 $\mathrm{mg} \mathrm{ml}^{-1}$ Similar zone of inhibition recorded at all the concentrations of E. coli and Pseudomonas aeruginosa. Eight $\mathrm{mm}$ zone of inhibition was recorded against Strephtococcus pneumoniae at 50, 25 and 12.5

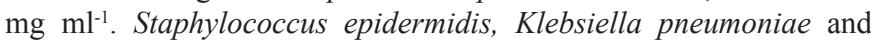
Shigella flexneri also showed $8 \mathrm{~mm}$ zone of inhibition at 25, 12.5 and $6.25 \mathrm{mg} \mathrm{ml}^{-1}$ concentrations.

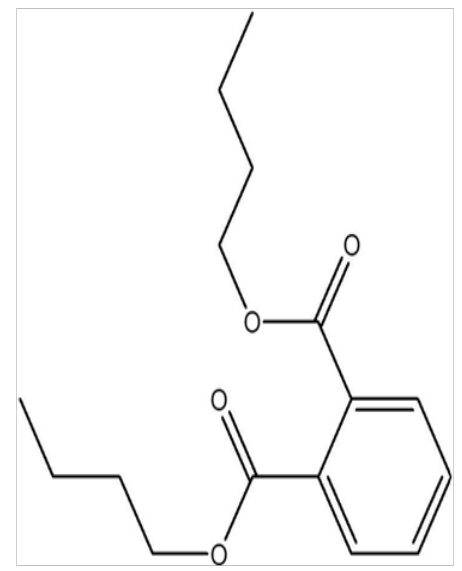

Figure 7 Structure of dibutyl phthalate.

\section{Discussion}

Bark of Mimusops elengi was extracted with hexane, chloroform, methanol and ethanol using Soxhlet apparatus. Then, the crude extract of chloroform was fractionated using $100 \%$ toluene and tolueneethyl acetate (75:25). These fractions were mixed together and rechromatographed using toluene and ethyl acetate (90:10), again fractionated using hexane and ethyl acetate with increasing percentage of ethyl acetate to obtain impure dibutyl phthalate. ${ }^{16}$ Dibutyl phthalate was cold extracted with ethyl acetate and eluted with hexane and ethyl acetate (9.5:0.5) from the stem of Ipomoea carnea..$^{17}$ Essential oil of flowers in Leea indica was obtained by hydro-distillation and re-extracted with diethyl ether and dried over anhydrous $\mathrm{Na}_{2} \mathrm{SO}_{4}$. Essential oil in hexane (1:40) ratio was analysed by GC-MS that revealed the presence of 17 compounds including the identification of 8 different types of phthalates..$^{18}$ In the present study, chloroform and methanol (9:1) fraction of methanol extract yielded $0.01 \%$ of dibutyl phthalate (Figure 8). The spectral data were identical to those reported in the literature ${ }^{19}$ (Figures 1-6).

Seven-day old culture of Streptomyces bangladeshensis mycelium was extracted twice with ethyl acetate and isolated bis-(2-ethylhexyl) phthalate from it. ${ }^{20}$ Bis (2-methylheptyl) phthalate isolated from the leaves of Pongamia pinnata increased $60 \%$ survival of Penaeus monodon infected with White Spot Syndrome Virus (WSSV) at 100 $\mu \mathrm{g} \mathrm{g}^{-1}$ of body weight of shrimp day ${ }^{-1} \cdot{ }^{21}$ Methanol extract of Nigella glandulifera seeds inhibited B16F10 murine melanoma cells by $43.7 \%$ and exhibited low cytotoxicity $(8.1 \%)$ at a concentration of $100 \mu \mathrm{g} \mathrm{ml}^{-1}$. Dried seeds of $N$. glandulifera extracted three times with four volumes of $95 \%$ methanol and fractionated with hexane and chloroform (1:0-0:1) to yield dioctyl phthalate (DOP). The compound 
also showed similar mode of action as that of $N$. glandulifera crude extract and inhibited murine tyrosine activity in B16F10 melanoma cells by $25.8 \%$ at a concentration of $10 \mu \mathrm{M}(22)$. In the present study, antibacterial activity of DBP showed $9 \mathrm{~mm}$ zone of inhibition against S. epidermidis, S. pneumoniae, E. coli, M. luteus, K. pneumoniae, S. flexneri, $V$. cholerae and $P$. aeruginosa at the concentration of 100 mg ml-1 (Figure 8). All the concentrations of DBP showed $9 \mathrm{~mm}$ zone of inhibition against $E$. coli and $P$. aeruginosa. DBP exhibited 8 $\mathrm{mm}$ zone of inhibition against $S$. pneumoniae at $50,25,12.5 \mathrm{mg} \mathrm{ml}^{-1}$ concentrations. At the concentrations of $25,12.5$ and $6.25 \mathrm{mg} \mathrm{ml}^{-1}$, DBP exhibited $8 \mathrm{~mm}$ zone of inhibition against $S$. epidermidis, $K$. pneumoniae and S. flexneri.

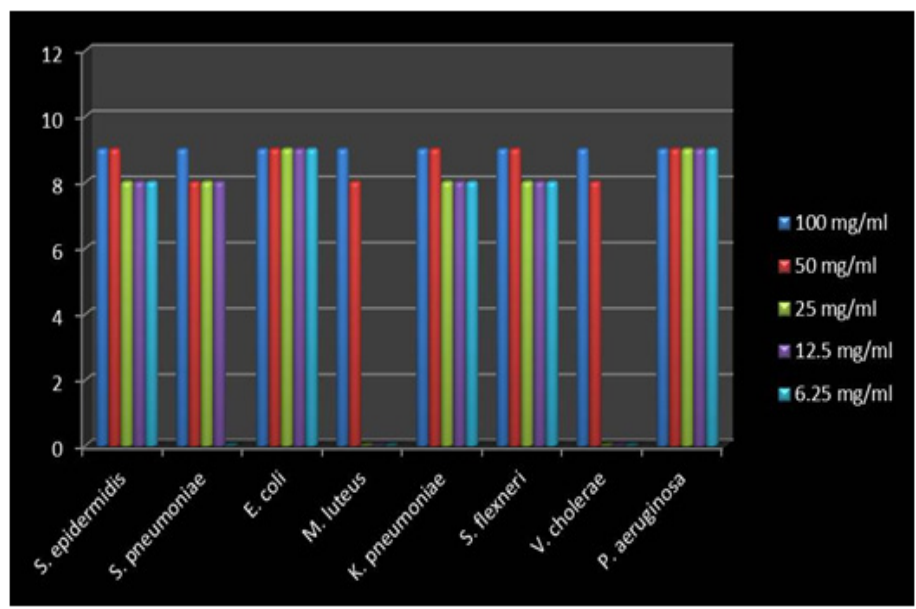

Figure 8 Antibacterial activity.

\section{Conclusion}

Dibutyl phthalate was isolated and characterized for the first time in Begoniaceae. It showed remarkable antibacterial activity. It can be tested against melanoma as its related compounds exhibited potential activity.

\section{Acknowledgements}

Miss T Mini Shobi gratefully acknowledges the Bharathidasan University, Tiruchirappalli, for awarding University Research Fellowship (05441/URF/K7/2013 dt.09.12.2013).

\section{Conflict of interest}

The authors declare that there is no conflict of interest.

\section{References}

1. Ramesh N, Viswanathan MB, Saraswathy A, et al. (2002) Phytochemical and antimicrobial studies of Begonia malabarica. $J$ Ethnopharmacol. 2002;79(1):129-132.

2. Kingston C. Ethnobotanical studies on wild edible plants of Kanyakumari district, Tamil Nadu. J Basic \& Appl Biol. 2007;1:32-34.

3. Ayyanar M, Ignacimuthu S. Endemic medicinal plants used by tribal people in Tirunelveli hills, Western Ghats of India. In: Reddy MV, editor. Wildlife Biodiversity Conservation. Daya Publishing House, New Delhi; 2008. p. 278-285.

4. Ariharan VN, Meena Devi VN, Rajakokhila M, et al. A new natural source for Vitamin-C. Int J Pl Env Sci. 2012;2:92-94.
5. Kalpanadevi V, Mohan VR (2012) In vitro antioxidant studies of Begonia malabarica Lam. and Begonia flocciferra Bedd. Asian Pacific Journal of Tropical Biomedicine. 2012;2(Supp 3):S1572$\mathrm{S} 1577$.

6. Taiz L, Zeiger E. Plant physiology. Sinauer Associates, Inc, Publishers Sunderland, Massachusetts, USA; 2002.

7. Wei H, Wen D, Liu X, et al. Constituents in petroleum ether and ethyl acetate extract fractions of Dracaena cochinensis (Lour.) S.C. Chen. Zhongguo Zhong Yao Za Zhi. 1998;23(10):616-618.

8. Nageswara Rao G, Mahesh Kumar P, Dhandapani VS, et al. Constituents of Cassia auriculata. Fitoterapia. 2000;71(1):82-83.

9. Cakir A, Mavi A, Yildirim A, et al. Isolation and characterization of antioxidant phenolic compounds from the aerial parts of Hypericum hyssopifolium L. by activity-guided fractionation. J Ethnopharmacol. 2003;87(1):73-83.

10. Wei YX, Wang JX. Studies on the chemical constituents of hypogeal part from Limonium bicolor. Zhong Yao Cai. 2006;29(11):1182-1184.

11. Ruan HL, Zhang Y, Zhang YH, et al. Studies on constituents from roots of Euphorbia hylonoma. Zhongguo Zhong Yao Za Zhi. 2006;31(9):742-744.

12. Liang R, Peng QJ. Analysis of constituents of essential oil from the skin of water caltrop. Zhong Yao Cai. 2006;29(1):24-26.

13. Xuan TD, Chung IM, Khanh TD, et al. Identification of phytotoxic substances from early growth of barnyard grass (Echinochloa crusgalli) root exudates. J Chem Ecol. 2006;32(4):895-906.

14. Mavar-Manga H, Haddad M, Pieters L, et al. Anti-inflammatory compounds from leaves and root bark of Alchornea cordifolia (Schumach. \& Thonn.) Müll. Arg. J Ethnopharmacol. 2008;115(1):25-29.

15. Perez C, Paul M, Bazerque P. Antibiotic assay by agar-well diffusion method. Acta Biol Medi Exp. 1990;15:113-115.

16. Ruikar AD, Gadkari TV, Phalgune UD, et al. Dibutyl phthalate, a secondary metabolite from Mimusops elengi. Chem Nat Compd. 2011;46(6):955-956.

17. Khatiwora E, Adsula VB, Kulkarni $M$, et al. Isolation and characterization of substituted dibutyl phthalate from Ipomoea carnea stem. Pharma Chem. 2013;5(5):5-10.

18. Srinivasan GV, Sharanappa P, Leela NK, et al. Chemical composition and antimicrobial activity of the essential oil of Leea indica (Burm. f.) Merr. flowers. Nat Prod Radiance. 2009;8(5):488-493.

19. Garg B, Bisht T, Ling YC. Sulfonated graphene as highly efficient and reusable acid carbocatalyst for the synthesis of ester plasticizers. RSC Advances. 2014;4(100):57297-57307.

20. Al-Bari MA, Bhuiyan MS, Flores ME, et al. Streptomyces bangladeshensis sp. nov., isolated from soil, which produces bis(2-ethylhexyl) phthalate. Int J Syst Evol Microbiol. 2005;55(Pt 5):1973-1977.

21. Rameshthangam P, Ramasamy P. Antiviral activity of bis (2-methylheptyl) phthalate isolated from Pongamia pinnata leaves against White Spot Syndrome Virus of Penaeus monodon Fabricius. Virus Res. 2007;126(1-2):38-44.

22. Nguyen DT, Nguyen DH, Lyun HL, et al. (2007) Inhibition of melanogenesis by dioctyl phthalate isolated from Nigella glandulifera Freyn. J Microbiol Biotechnol. 2007;17(10):1585-1590. 